\title{
Pesquisa
}

\section{COMPORTAMENTO DE RISCO NO TRÂNSITO ENTRE ESTUDANTES DE CIÊNCIAS SOCIAIS}

\author{
Jenniffer de Queiroz Batista (1) \\ Filemon Souza Lopes (2) \\ Anna Lúcia Fonsceca Leite (3) \\ Márcia Clébia Araújo (4)
}

\begin{abstract}
Resumo
O trânsito brasileiro hoje, possui índices alarmantes de infrações, vitimando milhares de pessoas todos os dias, dentre esses, um significativo número de jovens. O presente estudo objetiva conhecer a intenção, em termos de comportamento de risco, entre condutores jovens, alunos do Curso de Ciências Sociais da Universidade Regional do Cariri - URCA. Um protocolo com quinze questões pertinentes a temática foi distribuído a uma amostra de 28 estudantes, com idades entre 17 e 39 anos. Os resultados indicaram a necessidade de implementação de programas educativos para o trânsito nas universidades, pois, apesar de uma maioria apresentar comportamento adequado no trânsito, o número de condutores infratores ainda se mostrou alto. O agravante é o fato de que, sendo uma população universitária, acreditava-se ser mais esclarecida dos problemas sociais implicados.
\end{abstract}

Palavras-chaves: Estudantes universitários, Comportamento no trânsito, Ciências sociais.

\section{Introdução}

Os acidentes de trânsito e os fatores a eles associados, tais como; a péssima situação das rodovias nacionais, a falta de sinalização, o não cumprimento da legislação de trânsito, associados ao comportamento humano, por vezes negligente e inconseqüente, tornaram-se uma preocupação para a sociedade. Esta temática tem se constituído objeto de estudo em diversas áreas do conhecimento, notadamente nas ciências sociais e na saúde. No Brasil observam-se milhares de mortes por ano, o que nos sugere representar um problema de saúde Pública.

Segundo Jorge e Latorre (1994),

Neste panorama, os acidentes de trânsito correspondem a uma importante parcela. No mesmo período, eles vêm sendo responsáveis por mais da quarta parte do total de óbitos por causas externas, o que representou, segundo os dados de 1988, cerca de 30 mil mortes. A ocorrência dessas mortes nos Estados e Capitais brasileiras obedece a padrões diferentes. É 
importante conhecer sua distribuição segundo variáveis como sexo e idade, de forma a que esta sirva de embasamento para programas específicos que objetivem a reversão deste quadro. (P. 03-04).

Os acidentes de trânsito e os fatores a eles associados representam um problema social, havendo, assim a necessidade de ampliação de estudos, especialmente no campo das ciências sociais com o intuito de contribuir para compreensão do tema. O presente estudo, de natureza descritiva e exploratória, tem por objetivos comparar condutores jovens com e sem história de acidentes de trânsito quanto à faixa etária, comportamentos no trânsito e, quanto o perfil de um bom motorista, tendo em vista que a maior parte dos acidentes ocorrerem com jovens vejamos a citação abaixo:

A alta incidência de vítimas jovens em acidentes de trânsito, em diversas sociedades, vem sendo relacionada à falta de experiência na condução e de conhecimento dos veículos (geralmente veículos emprestados), além das características próprias da juventude, como a imaturidade, impulsividade, sentimento de onipotência, a busca de emoções, a necessidade de auto-afirmação perante o grupo de colegas e tendência de superestimar suas capacidades (LIMA, 2009. p.06).

\section{Método}

Trata-se de um estudo de natureza quantitativa e qualitativa, exploratório, com uma amostra de 28 alunos do Curso de Ciências Sociais da Universidade Regional do Cariri - URCA. A amostra foi de conveniência, por tratar-se do único curso de Ciências Sociais na Região do Cariri cearense. Nossa hipótese é de que, pela própria natureza do curso, e por tratar-se de alunos de licenciatura, em sua maioria futuros educadores, esses jovens se comportariam no trânsito de maneira mais satisfatória que a média da população geral.

O per[iodo do estudo compreendeu o semestre de 2009.2, mais precisamente no mês de ..... Os dados foram coletados através de um questionário auto-explicativo, não identificado, distribuído com os voluntários na própria universidade e recolhidos posteriormente.

O critério de inclusão foi ser aluno do curso de Ciências Sociais e ser condutor de veículos. O instrumento utilizado foi um questionário, de 15 perguntas, que constou com as seguintes variáveis: idade, sexo, tempo de exposição à direção, idade com que tirou habilitação, frequiência com que dirige; comportamento no trânsito visando definir por exemplo; uso do sinto de segurança, dirigir após beber, avanço de sinais, participação em rachas, ultrapassagens proibidas e envolvimento em acidentes de trânsito e, coletar opiniões sobre quais os critérios para ser um bom motorista para estes estudantes em que podemos obter respostas claras e objetivas.

\section{Resultados}

Quanto ao sexo dos participantes, dos 28 estudantes 39,3\% eram homens e 60,7\% eram mulheres. As idades variaram entre 17 e 39 anos, distribuídos de acordo com a tabela a seguir. 
Tabela 1 - Idade dos participantes. Crato, 2010.

\begin{tabular}{c|c|c}
\hline Idade & Freqüência & \% \\
\hline Menor que 18 anos & 1 & 3,6 \\
\hline $18-22$ Anos & 15 & 52,5 \\
\hline $23-27$ Anos & 8 & 28,6 \\
\hline $28-32$ Anos & 1 & 3,6 \\
\hline $33-37$ Anos & 2 & 7,2 \\
\hline Maior que 37 Anos & 1 & 3,6 \\
\hline Total & 28 & 100,0 \\
\hline
\end{tabular}

Também considerou-se importante conhecer a idade em que esses jovens começaram a dirigir. Os resultados encontram-se na tabela 2 , a seguir.

Tabela 2 - Idade em que começou a dirigir. Crato, 2010.

\begin{tabular}{c|c|c}
\hline Idade que começou a dirigir & Freqüîncia & \% \\
\hline Menos de 18 & 8 & 28,6 \\
\hline Mais de 18 & 20 & 71,4 \\
\hline Total & 28 & 100,0 \\
\hline
\end{tabular}

Com relação a idade que começou a dirigir, verificou-se que 28,6\% começou a dirigir antes dos 18 anos de idade. 71,4\% começaram a dirigir após os dezoito anos, denotando maior responsabilidade por parte da maioria dos participantes.

Tendo em vista serem estudantes universitários, pessoas com maior nível de instrução, ainda é alto o índice daqueles que não agem de acordo com a legislação vigente.

Outros estudos como os de Benincasa e Rezende ( 2006) e, Tsai, Anderson e Vaca (2008), destacam que, independente do gênero, esse péssimo hábito de dirigir sem habilitação é considerado um importante fator de risco para a ocorrência e gravidade de acidentes de trânsito.

Também foi considerada a idade em que os mesmos tiraram a sua primeira habilitação. Neste caso, o agravante foi que, $32,1 \%$ dos entrevistados ainda não possuíam habilitação. $25 \%$ não responderam a este questionamento.

O fato de cerca de $1 / 3$ de a população analisada ter aprendido a dirigir antes da idade mínima legal (18 anos de idade) reflete insuficiente conscientização quanto aos riscos de se ter um menor no volante, incluindo, na maioria das vezes, a anuência dos pais nesse tipo de comportamento de risco. Segundo estudos de Panichi e Wagner (2006), Andrade e Jorge (2000) e Sauer e Wagner (2003) , os adolescentes de classe social média e alta aprendem a dirigir precocemente, com idades variando de oito a treze anos, tendo geralmente os membros da família como seus instrutores e, este elemento, pode ser considerado também um fator de risco para acidente de trânsito. 
Com relação a frequiência que os entrevistados se expõem ao trânsito, os resultados indicaram que $46,4 \%$ raramente dirigem ; 32,1\% dirigem todos os dias; 3,6\% de 3 a 5 vezes por semana e 17,9\% até 3 vezes por semana.

Com relação à variável comportamento no trânsito, no item uso do cinto de segurança pode-se observar que $10,7 \%$ nunca usaram o cinto de segurança, quando na condição de condutores; $46,4 \%$ referiram usarem as vezes; 39,3\% usam sempre que dirigem e 3,6\% dos entrevistados não responderam a essa pergunta, como mostra a tabela 3 a seguir.

Tabela 3 - Frequência do uso do cinto de segurança. Crato, 2010.

\begin{tabular}{c|c|c}
\hline $\begin{array}{c}\text { Com que freqüência usa o } \\
\text { cinto de segurança? }\end{array}$ & Freqüência & \% \\
\hline Nunca & 3 & 10,7 \\
\hline Ás vezes & 13 & 46,4 \\
\hline Sempre & 11 & 39,3 \\
\hline Não Responderam & 1 & 3,6 \\
\hline Total & 28 & 100,0 \\
\hline
\end{tabular}

Quanto ao uso do cinto de segurança, apenas 39,3\% dos jovens da amostra, utilizaram sempre este equipamento na condição de condutores, ou seja, ainda aproximadamente $60 \%$ da população estudada não o utilizam com freqüência. Trata-se de um índice inquietante, já que a legislação brasileira obriga a este procedimento. Os percentuais apresentados nesta pesquisa em relação ao uso de cinto de segurança, são assustadoramente menores que os de outros estudos, que estão entre 80 e 90\% (ANDRADE et al, 2003; MARTIN e VIZZOTTO, 2003).

Estas observações sugerem que, talvez, as inúmeras campanhas educativas realizadas pelos órgãos competentes possam não estar atingindo os jovens da faixa etária estudada. A carência de fiscalização no trânsito também contribui para este tipo de infração.

Acreditamos ser importante verificar o comportamento após ingestão de álcool. Observe-se a tabela a seguir.

Tabela 6 - Dirige após uso de bebida alcoólica?. Crato, 2010.

\begin{tabular}{c|c|c}
\hline $\begin{array}{c}\text { Dirige após uso de bebida } \\
\text { alcoólica? }\end{array}$ & Freqüência & $\%$ \\
\hline Sim & 6 & 21,4 \\
\hline Não & 18 & 64,3 \\
\hline Às vezes & 4 & 14,3 \\
\hline Total & 28 & 100,0 \\
\hline
\end{tabular}


Dos entrevistados no item dirigir após ingestão de bebida alcoólica, observou-se que 21,4\% dirigem após beber; 64,4\% não dirigem após ingerir bebida alcoólica e 14,3\% as vezes dirigem alcoolizados.

Diversos estudos sugerem uma evidente associação entre o uso do álcool e a presença de vítimas fatais nos acidentes de trânsito. Essa associação é observada principalmente na população jovem, abaixo de 21 anos de idade e, na maioria dos países, independente do grau de desenvolvimento (LOWENSTEIN e KOZIOLMCLAIN, 2001; PECK et al., 2008)

Estudo recente aponta que dentre 2.360 vítimas fatais por acidentes de trânsito avaliadas no Estado de São Paulo, 47\% tinham álcool no sangue (alcoolemia) no momento do acidente (LEYTON, GREVE, CARVALHO e MUÑOZ, 2005).

Quanto a outros comportamentos de agravos no trânsito, no item avançar sinal vermelho, observamos que 46,4\% nunca o fizeram, 42,9 avançaram algumas vezes e 10,7\% raramente avançaram um sinal vermelho.

Ao serem questionados sobre a participação em rachas $85,7 \%$ responderam nunca terem participado de rachas e 14,3\% responderam ter participação aleatória.

Com relação a ter realizado ultrapassagens proibidas 32,1\% já realizaram e 67,7\% não realizaram. Quanto ao envolvimento em acidentes de trânsito 14,3\% destes já se envolveram, e 82,1\% afirmaram nunca terem se envolvido em acidentes de trânsito.

Apesar dos estudantes reconhecerem que o desrespeito à sinalização foi um dos principais fatores que contribuem na ocorrência do acidente de trânsito, uma considerável parcela dos acadêmicos referiu avançar sinal vermelho, participarem de rachas e procederem ultrapassagens proibidas.

Este comportamento infrator e de alto risco para acidentes de trânsito verificado nos jovens deste estudo corrobora com as observações de outras pesquisas anteriormente publicadas, citando que os jovens tendem a assumir comportamentos de risco à saúde e que são as principais vítimas de acidentes de trânsito (ANDRADE et al., 2003; ANDRADE e JORGE, 2000; ANDRADE et al., 2003).

A alta incidência de vítimas jovens em acidentes de trânsito, em diversas sociedades, vem sendo relacionada à falta de experiência na condução e de conhecimento dos veículos (geralmente veículos emprestados), além das características próprias da juventude, como a imaturidade, impulsividade, sentimento de onipotência, a busca de emoções, a necessidade de auto-afirmação perante o grupo de colegas e tendência de superestimar suas capacidades(ANDRADE e JORGE, 2000). Como agravante, os jovens, geralmente, consomem mais bebidas alcoólicas e drogas do que os adultos, bem como tendem a exceder mais os limites de velocidade e a desrespeitar outras normas de segurança no trânsito, o que, sabidamente, aumenta as chances de ocorrências de acidentes (BENINCASA e RESENDE, 2006; ANDRADE e JORGE, 2000).

\section{Conclusão}

Com as facilidades cada vez maiores para aquisição de bens automóveis, o aumento da frota de veículos tende a crescer mais que o sistema viário pode suportar. Dessa forma, os acidentes de trânsito se tornaram uma das principais causas de mortalidade no âmbito mundial, e no Brasil, o trânsito é considerado um dos piores e mais perigosos do mundo. Infelizmente, Foram observados diversos comportamentos inadequados e de risco para acidentes de trânsito entre os jovens universitários deste estudo. O levantamento das características 
comportamentais no trânsito entre indivíduos jovens, possibilitaria a criação e aprimoramento de estratégias para reduzir a ocorrência, gravidade e conseqüências deste tipo de acidente.

Os resultados deste estudo nos leva a crer que há necessidade de implementação de programas educativos nas universidades, pois, a educação é o meio mais eficaz para gerar mudanças de comportamento imprescindíveis para a diminuição dos acidentes de trânsito. Embora seus efeitos só possam ser sentidos a médio e a longo prazos, eles tendem a serem mais intensos e duradouros.

Para que estes programas de prevenção verdadeiramente funcionem é necessária a participação da comunidade acadêmica para discutir, apontar, resolver, propor, refletir e decidir sobre as formas de melhorar o trânsito, propondo inclusive, saídas, condutas e normas sobre as vias públicas, as leis e os programas de educação para o trânsito (CHAMMÉ, 1997).

Sugere-se também um maior controle da propaganda, tanto daquela que associa velocidade à vitalidade e à saúde quanto da que associa ingestão de bebidas alcoólicas à liberdade e ao prazer.

Outras alternativas perpassam por políticas públicas mais adequadas, tais como uma melhoria do transporte de massa, investimento na qualidade das obras viárias que intensifiquem uma melhoria do fluxo de veículos, redução de impostos para pessoas que não se envolvem diretamente com acidentes de trânsito, dentre outros.

Espera-se que este estudo proporcione uma reflexão os jovens universitários, com conseqüentes mudanças de comportamento ainda nos próximos anos de graduação, acompanhados de um amadurecimento da personalidade destes jovens para as questões aqui discutidas.

\section{Referências}

ANDRADE SM, JORGE MHPM. Características das vítimas por acidentes de transporte terrestre em município da Região Sul do Brasil. Rev. Saúde Públ. 2000;34(2):149-56.

ANDRADE SM, SOARES DA, BRAGA GP, MOREIRA JH, BOTELHO FMN. Comportamentos de risco para acidentes de trânsito: um inquérito entre estudantes de medicina na região sul do Brasil. Rev. Ass. Med. Bras. 2003;49(4):439-44.

BENINCASA M, REZENDE MM. Percepção de fatores de risco e de proteção para acidentes para acidentes e trânsito entre adolescentes. Boletim de Psicologia. 2006;125:241-56.

CHAMMÉ, S. J. O século e a crise. Saúde: um processo em constante construção. Marília. (Tese de LivreDocência ) UNESP/Campus Marília) 1997b.

JORGE, Maria Helena P. De Mello; LATORRE, Maria Rosário D. Acidentes de transito no Brasil: dados e tendências. Cad.saúde Pública,vol10,suppl.Rio de Janeiro.1004

LEYTON V, GREVE JMD'A, CARVALHO DG, MUÑOZ DR. Perfil epidemiológico das vítimas fatais por acidente de trânsito e a relação com o uso do álcool. Revista Saúde, Ética e Justiça. 2005;10(1/2):12-8.

LOWENSTEIN SR, KOZIOL-MCLAIN J. DRUGS and traffic crash responsibility: a study of injured motorists in Colorado. J Trauma. 2001;50(2):313-20.

MARIN L, VIZZOTTO MM. Comportamentos no trânsito: um estudo epidemiológico com estudantes universitários. Cad. Saúde Pública. 2003;19(2):515-23.

PANICHI, RMD, WAGNER A. Comportamento de risco no trânsito: revisando a literatura sobre as variáveis preditoras da condução perigosa na população juvenil. Revista Interamaricana de Psicologia. 2006;40(2):159-61.

PEREIRA, de Oliveira Lima. REVISTA ELETRONICA DE ENFERMAGEM Comportamentos de jovens no trânsito: um inquérito entre acadêmicos de enfermagem UFG,2009. 06p.

PECK RC, GEBERS MA, VOAS RB, ROMANO E. The relationship between blood alcohol concentration (BAC), age, and crash risk. J Safety Res. 2008;39(3):311-9.

SAUER MTN, WAGNER MB. Acidentes de trânsito fatais e sua associação com a taxa de mortalidade infantil e adolescência. Cad. Saúde Pública. 2003;19(5):1519-26. 
TSAI VW, ANDERSON CL, VACA FE. Young female drivers in fatal crashes: recent trends, 1995-2004. Traffic Inj Prev. 2008;9(1):65-9.

\section{Sobre os autores:}

(1) Jenniffer de Queiroz Batista é Acadêmico de Ciências Sociais pela Universidade Regional do Cariri URCA. E-mail: jenniffer_batista@hotmail.com

(2) Filemon Souza Lopes é Acadêmico de Ciências Sociais pela Universidade Regional do Cariri URCA. E-mail: fileecs@gmail.com

(3) Anna Lúcia Fonseca Leite é Acadêmica de Ciências Sociais pela Universidade Regional do Cariri URCA.

(4) Márcia Clébia Araújo é Acadêmica de Ciências Sociais pela Universidade Regional do Cariri URCA.

\section{Como citar este artigo (Formato ISO):}

BATISTA, J.Q.; LOPES, F.S.; LEITE, A.L.F.; ARAÚJO, M.C. Comportamento de Risco no Trânsito entre Estudantes de Ciências Sociais. Id on Line Revista de Psicologia, Fevereiro de 2011, vol., n.13, p.63-69. ISSN 1981-1189. 